\title{
Epidemiological Characteristics and Spatiotemporal Analysis of Mumps from 2004 to 2018 in Chongqing, China
}

\author{
Hua Zhu ${ }^{1}$, Han Zhao ${ }^{2}$, Rong Ou ${ }^{3}$, Haiyan Xiang ${ }^{1}$, Ling Hu ${ }^{1}$, Dan Jing ${ }^{1}$, Manoj Sharma ${ }^{4}$ and \\ Mengliang Ye ${ }^{1, *(\mathbb{D})}$ \\ 1 Department of Epidemiology and Health Statistics, School of Public Health and Management, Chongqing \\ Medical University, Chongqing 400016, China \\ 2 Chongqing Municipal Center for Disease Control and Prevention, Chongqing 400042, China \\ 3 Department of Medical Informatics Library, Chongqing Medical University, Chongqing 400016, China \\ 4 Department of Behavioral and Environmental Health, Jackson State University, Jackson, MS 39213, USA \\ * Correspondence: yemengliang@cqmu.edu.cn; Tel.: +86-153-1093-9053
}

Received: 14 July 2019; Accepted: 19 August 2019; Published: 22 August 2019

\begin{abstract}
Mumps vaccines have been widely used in recent years, but frequent mumps outbreaks and re-emergence around the world have not stopped. Mumps still remains a serious public health problem with a high incidence in China. The status of mumps epidemics in Chongqing, the largest city in China, is still unclear. This study aimed to investigate the epidemiological and spatiotemporal characteristics of mumps and to provide a scientific basis for formulating effective strategies for its prevention and control. Surveillance data of mumps in Chongqing from January 2004 to December 2018 were collected from the National Notifiable Diseases Reporting Information System. A descriptive analysis was conducted to understand the epidemiological characteristics. Hot spots and spatiotemporal patterns were identified by performing a spatial autocorrelation analysis, a purely spatial scan, and a spatiotemporal scan at the county level based on geographic information systems. A total of 895,429 mumps cases were reported in Chongqing, with an annual average incidence of 36.34 per 100,000 . The yearly incidence of mumps decreased markedly from 2004 to 2007, increased sharply from 2007 to 2011, and then tapered with a two-year cyclical peak after 2011. The onset of mumps showed an obvious bimodal seasonal distribution, with a higher peak of mumps observed from April to July of each year. Children aged 5-9 years old, males, and students were the prime high-risk groups. The spatial distribution of mumps did not exhibit significant global autocorrelation in most years, but local indicators of spatial autocorrelation and scan statistics detected high-incidence clusters which were mainly located in the midwestern, western, northeastern, and southwestern parts of Chongqing. The aggregation time frame detected by the purely temporal scan was between March 2009 and July 2013. The incidence of mumps in Chongqing from 2004 to 2018 featured significant spatial heterogeneity and spatiotemporal clustering. The findings of this study might assist public health agencies to develop real-time space monitoring, especially in the clustering regions and at peak periods; to improve immunization strategies for long-term prevention; and to deploy health resources reasonably.
\end{abstract}

Keywords: mumps; epidemiology; spatiotemporal analysis; cluster

\section{Introduction}

Mumps, an acute respiratory infectious disease caused by the mumps virus, is transmitted to a person primarily through contact, fomites, and droplets [1]. The main clinical manifestation of mumps is unilateral or bilateral parotid gland swelling, accompanied by pain and fever [2]. Although its 
common symptoms seem mild, mumps can cause serious complications such as permanent deafness, encephalitis, pancreatitis, oophoritis, and orchitis, which may result in disability or death and bring a heavy economic burden to families and societies [3,4]. This disease is highly contagious and often occurs in childhood [5]. Since the mumps vaccine was approved for use in 1967, mumps has become a vaccine-preventable infectious disease, and the incidence has rapidly and substantially reduced. By the end of 2017, the mumps vaccine had been introduced worldwide in 122 countries [6]. The specific effect of vaccination is related to factors such as age, coverage, and inoculation times. However, the recovery and outbreaks of mumps have not stopped, even in some developed countries with higher immunization rates, such as the United States [7], France [8], Britain [9], and Australia [10], which has once again aroused concern and attention. Increasing evidence has suggested that vaccine-induced immunity impairment is not sufficient to fully prevent mumps outbreaks and that an advanced strategy of immunotherapy is required-three doses of vaccine rather than two [11-14]. The number of mumps cases in China has declined in recent years, but it ranked first among all countries in 2017 [15]. From 2004 to 2017, the total number of mumps cases in China reached 402,520, accounting for $51.41 \%$ of the total global cases [15]. In 2008, China added the mumps-containing vaccine (MuCV) to its national immunization program, providing children aged 18-24 months one dose of measles-mumps-rubella (MMR) vaccine free of charge. However, only a few economically developed areas implemented the two doses of the vaccine. Therefore, the level of immunization in China as a developing country lags behind many developed countries, which have widely implemented the second dose of the vaccine schedule. Mumps is still a significant public health concern in China and thus deserves to be explored and studied.

Geographic information systems (GIS) are widely applied in the field of public health [16] and are an effective tool to describe the spatiotemporal distribution, evolution, and aggregation of a disease as well as visualize morbidity and clustering regions on a map $[17,18]$. Researchers have generally applied spatial autocorrelation and space-time scan techniques to explore the spatial and temporal characteristics of various communicable diseases [19-23], which has contributed to the adoption of improved preventive and control measures for regions and periods with different risk levels. Previous studies on mumps in terms of spatial and temporal analyses showed spatial dependence and heterogeneity in several regions of China, such as Shandong [24], Guangxi [25], and Gansu [26]. Chongqing, a central-government-controlled municipality located in the southwest of China and the upper reaches of the Yangtze River, is the largest and most populous city in China. To the best of our knowledge, no study has been carried out on the epidemiological and spatiotemporal features of mumps in Chongqing, which has remained a knowledge gap.

Therefore, in this study, we conducted a descriptive and geographical analysis at the county level, based on the surveillance data of mumps in Chongqing from 2004 to 2018, to identify the epidemiological characteristics and discover the spatiotemporal pattern of mumps.

\section{Materials and Methods}

\subsection{Study Area}

Chongqing $\left(28^{\circ} 10^{\prime}-32^{\circ} 13^{\prime} \mathrm{N}, 105^{\circ} 11^{\prime}-110^{\circ} 11^{\prime} \mathrm{E}\right)$, the largest city and economic center of southwest China, covers a land area of $824,000 \mathrm{~km}^{2}$ with 38 districts and counties and had an inhabitant population of about 31.01 million by the end of 2018 (Figure 1). Chongqing is mainly dominated by mountains $(76 \%)$ and hills and belongs to a subtropical humid monsoon climate zone with a moist climate, ample precipitation, and four distinct seasons. The weather is relatively moderate, with an annual average temperature of $16-18^{\circ} \mathrm{C}$. The main urban area of Chongqing consists of nine districts, namely, Yuzhong, Jiangbei, Nanan, Jiulongpo, Shapingba, Dadukou, Beibei, Yubei, and Banan, which are pinpointed in Figure 1. 


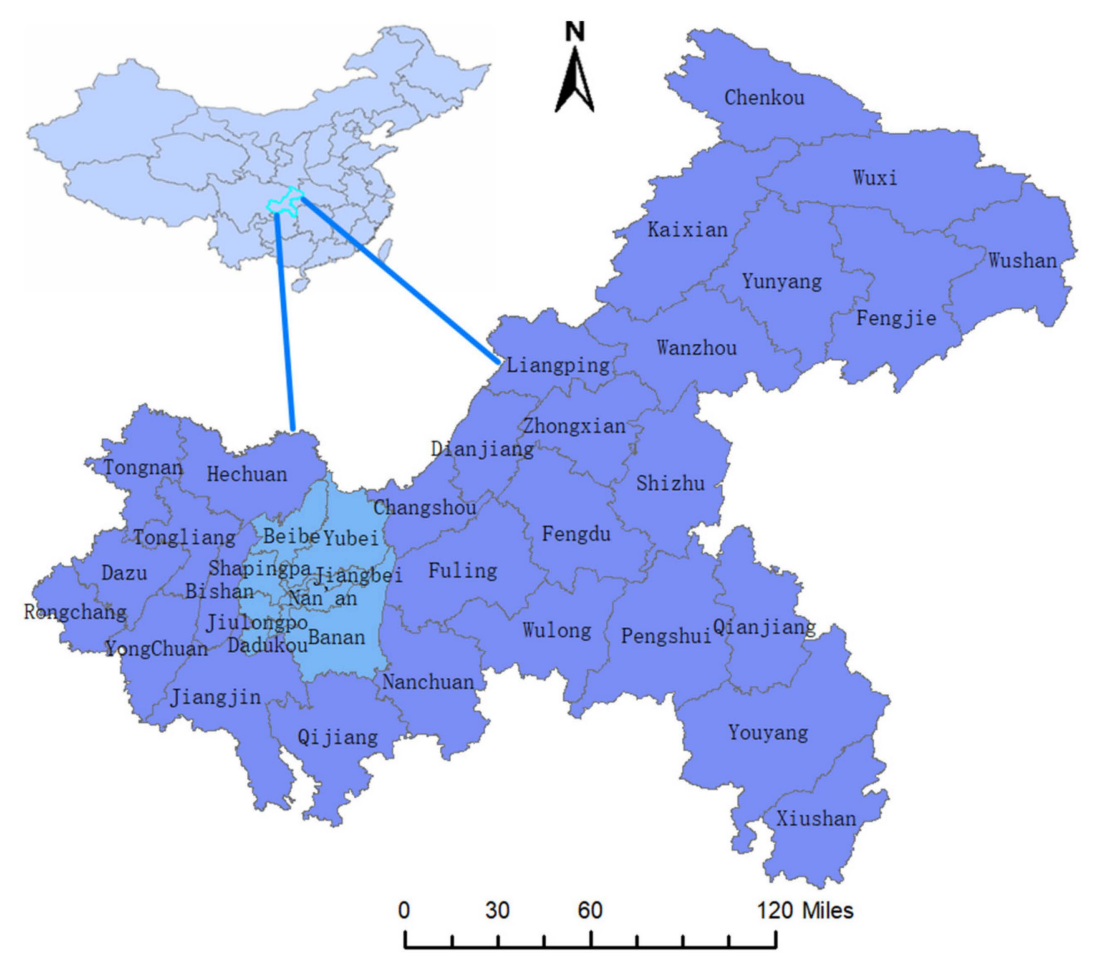

Figure 1. The geographical location and administrative division of Chongqing at the county level in China. The blue part represents the nine main urban districts.

\subsection{Data Collection and Management}

The National Notifiable Diseases Reporting Information System (NNDRIS), established in 2004, covers all kinds of medical and health institutions at all levels throughout the country [27]. Patients with mumps as a Class $C$ infectious disease are diagnosed by professional doctors on the basis of the clinical manifestations and laboratory examination results according to diagnostic criteria for mumps promulgated by China's Ministry of Health. According to the regulations of the Health Administrative Department under the State Council, doctors must fill out infectious disease report cards, which are collected by epidemic report management personnel of hospitals or public health institutions and delivered to the NNDRIS within $24 \mathrm{~h}$. Surveillance data of mumps from January 2004 to December 2018 in various districts and counties of Chongqing were obtained from NNDIRS, including sociodemographic characteristics, date of onset, address, and so on. The occupations of patients with mumps were classified according to the occupational classifications set by the standardized form on the infectious disease report card of the People's Republic of China [28]. The incidence of mumps was calculated by dividing the number of new reported mumps cases by the population and expressed as cases per 100,000 persons. Population data were provided by the Chongqing Center for Disease Control and Prevention. The vector maps of China and Chongqing came from the National Basic Geographic Information System.

\subsection{Spatial Autocorrelation Analysis}

In this study, the purpose of the spatial autocorrelation analysis was to probe the correlation from the spatial domain and search for potential cluster regions, which mainly included global and local spatial autocorrelation analyses. The global spatial autocorrelation with the indicator of global Moran's I statistic reflected the spatial dependence of mumps incidence in a global area. The Moran's I ranged from -1 to 1 . An $I>0$ and an $I<0$ with statistical significance represented positive and negative spatial autocorrelation, respectively. An $I=0$ indicated no spatial autocorrelation, which meant that the mumps was randomly distributed throughout Chongqing. $p$-values $(p<0.05)$ and Z-scores $(|Z|<1.96)$ 
were utilized to determine the statistical significance of Moran's I. Specific cluster patterns and regions were detected by local spatial autocorrelation, which was expressed by local indicators of spatial autocorrelation (LISA) $[29,30]$. Four spatial patterns could be seen intuitively in LISA maps: high-high (high-incidence regions surrounded by high-incidence regions); high-low (high-incidence regions surrounded by low-incidence regions); low-low (low-incidence regions surrounded by low-incidence regions); and low-high (low incidence surrounded by high incidence).

\subsection{Scan Statistics}

SaTScan software was used to perform retrospective purely temporal, purely spatial, and space-time scan analyses, with a discrete Poisson model only for high-incidence areas. The basic idea of scan analysis is to set up a scanning window that can move in time and/or space, and the size and location of the window change dynamically [31]. The windows of purely temporal, purely spatial, and space-time scans are defined by an interval, either circular or elliptical, corresponding to the geographic areas and a cylinder with a circular or elliptical base, respectively. The bottom and height of the cylinder correspond to the geographical area and the length of time, respectively. In the scan statistics, the null hypothesis was that the relative risk $(R R)$ of the disease was the same within the scan window compared to the outside, which suggested that the spatial and/or temporal distribution of mumps was completely random, while the alternative hypothesis was that the risk of disease within the window was higher than the outside. In this study, the maximum spatial cluster size was specified as $20 \%$ of the population at risk in the spatial window, and the maximum temporal cluster size as $50 \%$ of the study period in the time window. Then, the log likelihood ratio $(L L R)$ was calculated on the basis of the actual and theoretical number of cases inside and outside the window, and the $p$-values were computed through a Monte Carlo hypothesis test. The cluster with the largest $L L R$ value was considered as the most likely cluster. In the purely spatial and space-time analyses, SaTScan also identified secondary clusters in the dataset, in addition to the most likely cluster, and ordered them according to their likelihood ratio test statistic. The number of Monte Carlo simulations was set to the default value of 999 .

\subsection{Statistical Software}

In this study, a descriptive statistical method was used to investigate the population distribution and seasonal characteristics of mumps cases. Spatial autocorrelation analysis was conducted using OpenGeoda software version 1.2.0 [32]. The three scan methods above were performed using SaTScan software version 9.5 (Martin Kulldorff, National Cancer Institute, Bethesda, MD, USA). Geographical distribution, local clustering regions of annual incidence, and scanning results were mapped and visualized by ArcGIS software version 10.2 (ESRI, Redlands, CA, USA). All results were considered statistically significant when the $p$-value for both sides was less than 0.05 .

\section{Results}

\subsection{Epidemiological Characteristics}

A total of 895,429 mumps cases were reported in Chongqing from 2004 to 2018, with an annual average reported incidence of 36.34 per 100,000 (ranging from 17.55 per 100,000 in 2007 to 59.14 per 100,000 in 2011). The changing tendency of mumps occurrence in the whole of Chongqing was divided into three stages: the incidence of mumps decreased from 2004 to the lowest level in 2007; then, it increased to the peak in 2011; finally, from 2011 to 2018, the overall epidemic trend was downward with a two-year periodic peak. There were 93,655 male cases and 65,526 female cases reported, respectively. The average sex ratio of male to female was 1.42:1, higher than that of Chongqing's total population. With regard to the age distribution, cases of patients aged 5-9 years ranked first, accounting for $48.8 \%$ of the total cases, followed by patients aged 10-14 (24.2\%) and patients aged $0-4(15.1 \%)$. In terms of the occupation classification, students were the leading group $(62.8 \%)$, followed by kindergarten 
children (21.3\%) and scattered children (children who have not reached the age of 3 years to attend kindergarten or are taken care of by their family members) $(8.0 \%)$. The prevalence of mumps had obvious seasonality. The primary peak period of mumps occurred from April to July (57.5\%), while the second peak occurred from November to January in the next year (20.0\%). All of the results above are shown in Figure 2.

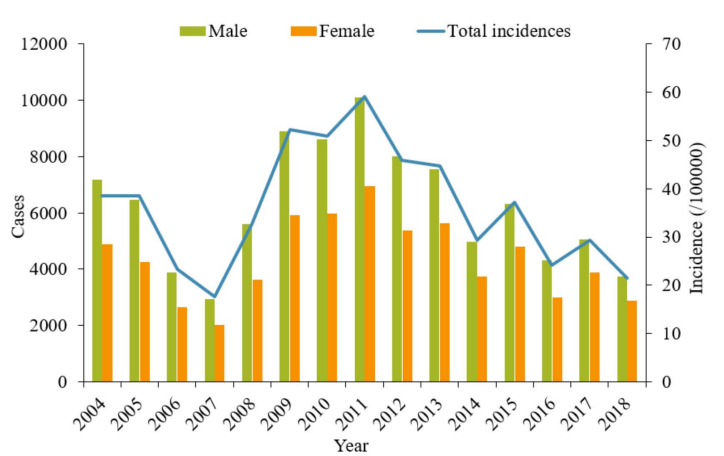

(a)

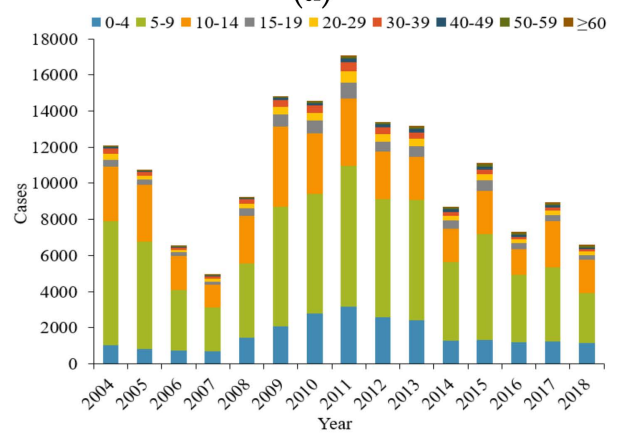

(c)

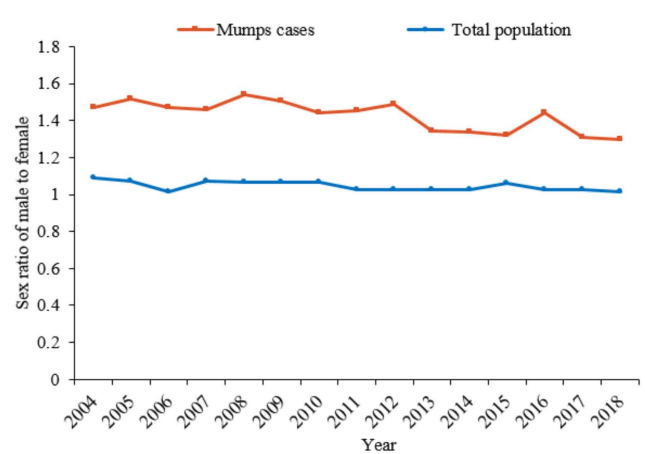

(b)

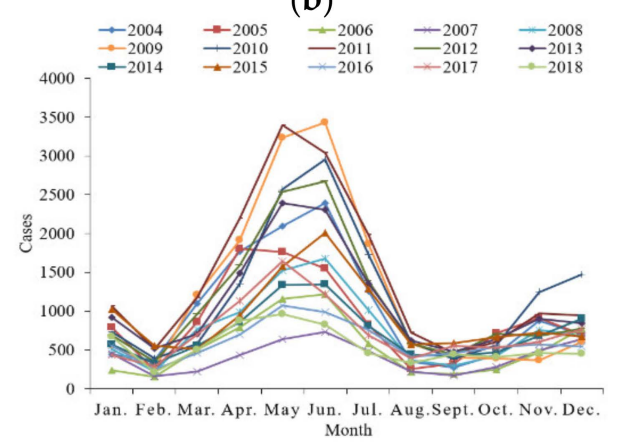

(d)

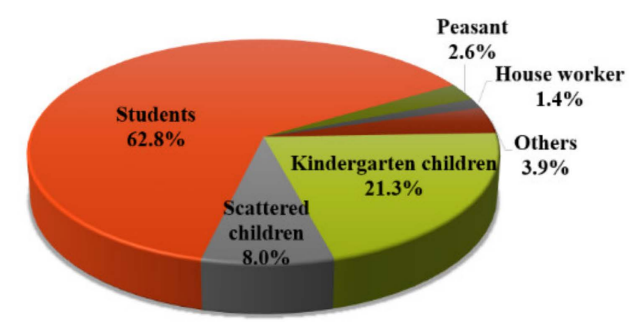

(e)

Figure 2. Epidemiological characteristics of mumps in Chongqing from 2004 to 2018. (a) The annual case number of mumps across different genders and the annual incidence of total mumps cases. (b) The annual sex ratio of male to female for mumps cases and total population. (c) The aged distribution of mumps cases. (d) The monthly distribution of mumps cases. (e) The occupational distribution of mumps cases.

\subsection{Incidence Maps}

Annual incidence maps of mumps infection across the years 2004-2018 (Figure 3) indicated that the location of high-incidence counties (districts) in Chongqing changed but was mainly in the west and northeast. The top five districts in terms of annual incidence were Jiulongpo $(61.92$ per 100,000), Beibei (61.57 per 100,000), Nan'an (59.98 per 100,000), Shapingba (58.58 per 100,000), and Dadukou (51.39 per 100,000), all located in the main urban area of Chongqing city. Mumps occurrence was more prevalent and the geographical distribution more heterogeneous during the period of 2009-2013. Nevertheless, over the last few years, the mumps epidemic showed a decreasing trend, accompanied by smaller regional variation. 

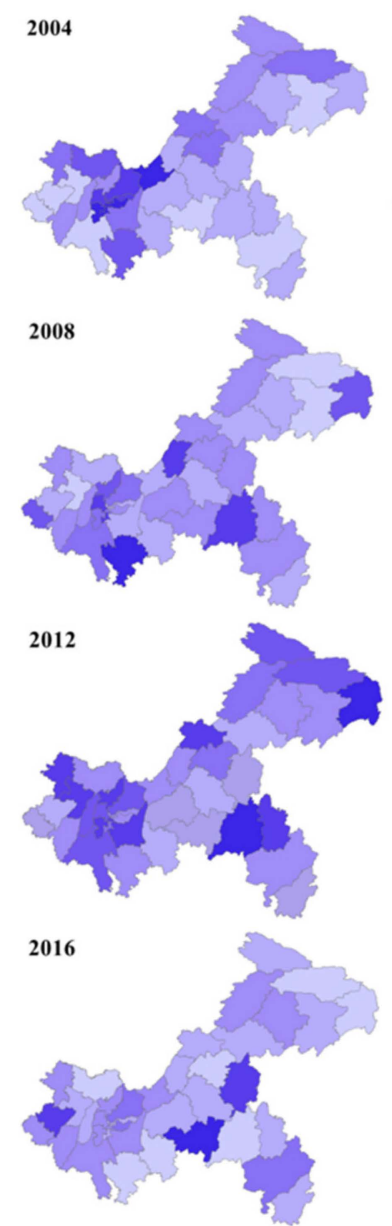
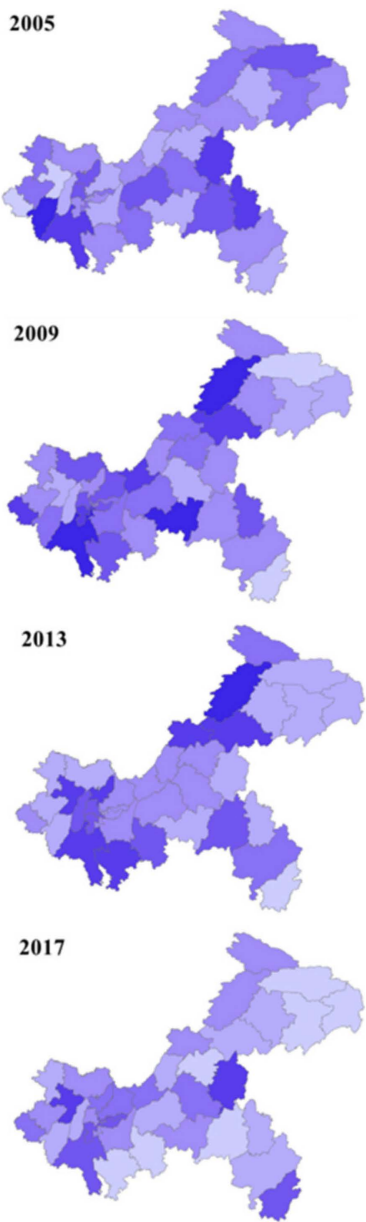
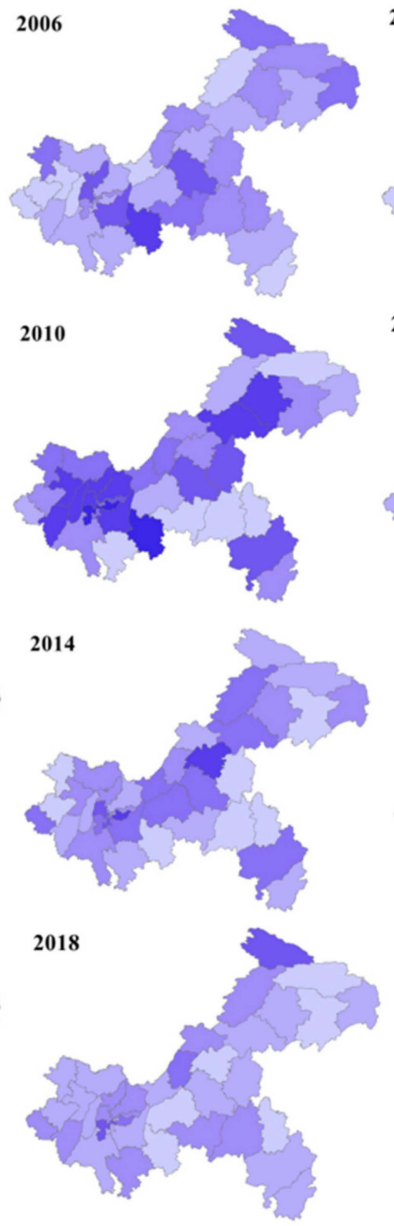
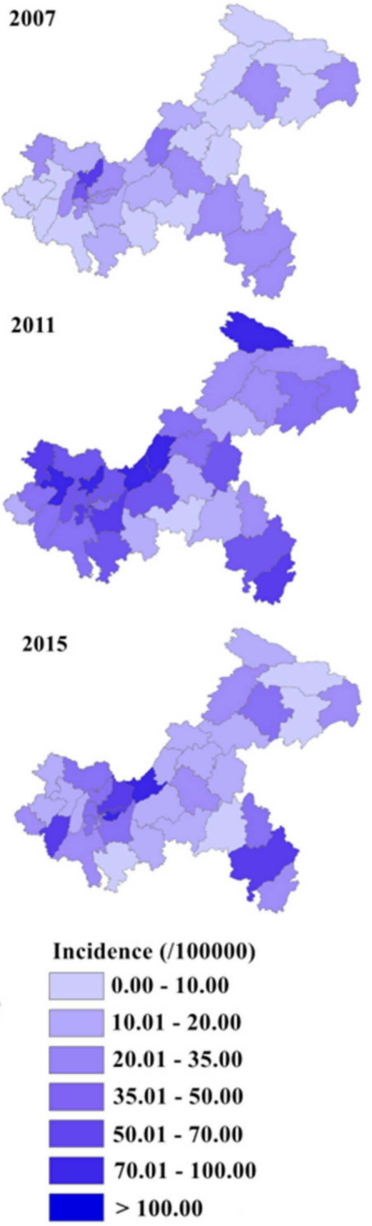

Figure 3. Annual incidence maps of mumps in Chongqing from 2004 to 2018.

\subsection{Spatial Autocorrelation Analysis}

The results of the global autocorrelation analysis in Chongqing in 2004-2018 are listed in Table 1. Significant positive global correlations existed in 2004, 2007, and 2015, and the distribution of mumps demonstrated no spatial correlation over the entire region in other years. According to the yearly LISA cluster maps of mumps, the local spatial autocorrelation analysis detected 16 high-high, 14 low-low, 13 low-high, and 9 high-low clusters (Figure 4). The hot spots (high-high clusters) were mainly observed in nine main urban districts, including Bishan, Hechuan, Rongchang, Wulong, Wanzhou, and Chengkou. No hot spots were found in 2005, 2009, 2012, 2017, and 2018.

\subsection{Spatial Cluster Analysis}

The purely spatial cluster analysis indicated that the spatial distribution of mumps was not random in Chongqing between 2004 and 2018. The spatial scan identified the 15 most likely clusters and 8 secondary clusters for high-incidence areas of mumps with statistical significance (Table 2). The number of counties included in each cluster ranged from one to eight. The exact locations of clusters varied every year, but they were mainly in the west, midwest, and northeast of Chongqing (Figure 5). 
Table 1. Global spatial autocorrelation of mumps in Chongqing from 2004 to 2018.

\begin{tabular}{cccccc}
\hline Year & Moran's $I$ & Z-Score & $p$-Value & Mean & SD \\
\hline 2004 & 0.4511 & 4.2581 & 0.001 & -0.0247 & 0.1117 \\
2005 & -0.1398 & -1.117 & 0.134 & -0.0227 & 0.1048 \\
2006 & 0.0564 & 0.7658 & 0.206 & -0.0244 & 0.1055 \\
2007 & 0.1763 & 1.979 & 0.045 & -0.029 & 0.1037 \\
2008 & -0.0838 & -0.5153 & 0.315 & -0.0301 & 0.1042 \\
2009 & 0.0868 & 1.0407 & 0.142 & -0.0279 & 0.1102 \\
2010 & 0.0508 & 0.6996 & 0.235 & -0.0265 & 0.1105 \\
2011 & 0.1251 & 1.5539 & 0.063 & -0.0337 & 0.1022 \\
2012 & -0.0225 & 0.049 & 0.436 & -0.0271 & 0.0945 \\
2013 & 0.093 & 1.0947 & 0.129 & -0.0271 & 0.1096 \\
2014 & -0.0498 & -0.2262 & 0.426 & -0.0248 & 0.1108 \\
2015 & 0.2124 & 2.4075 & 0.02 & -0.0273 & 0.0995 \\
2016 & -0.0888 & -0.6509 & 0.271 & -0.0223 & 0.1023 \\
2017 & 0.0376 & 0.6416 & 0.252 & -0.0328 & 0.1096 \\
2018 & -0.0359 & -0.0229 & 0.464 & -0.0335 & 0.1053 \\
\hline
\end{tabular}
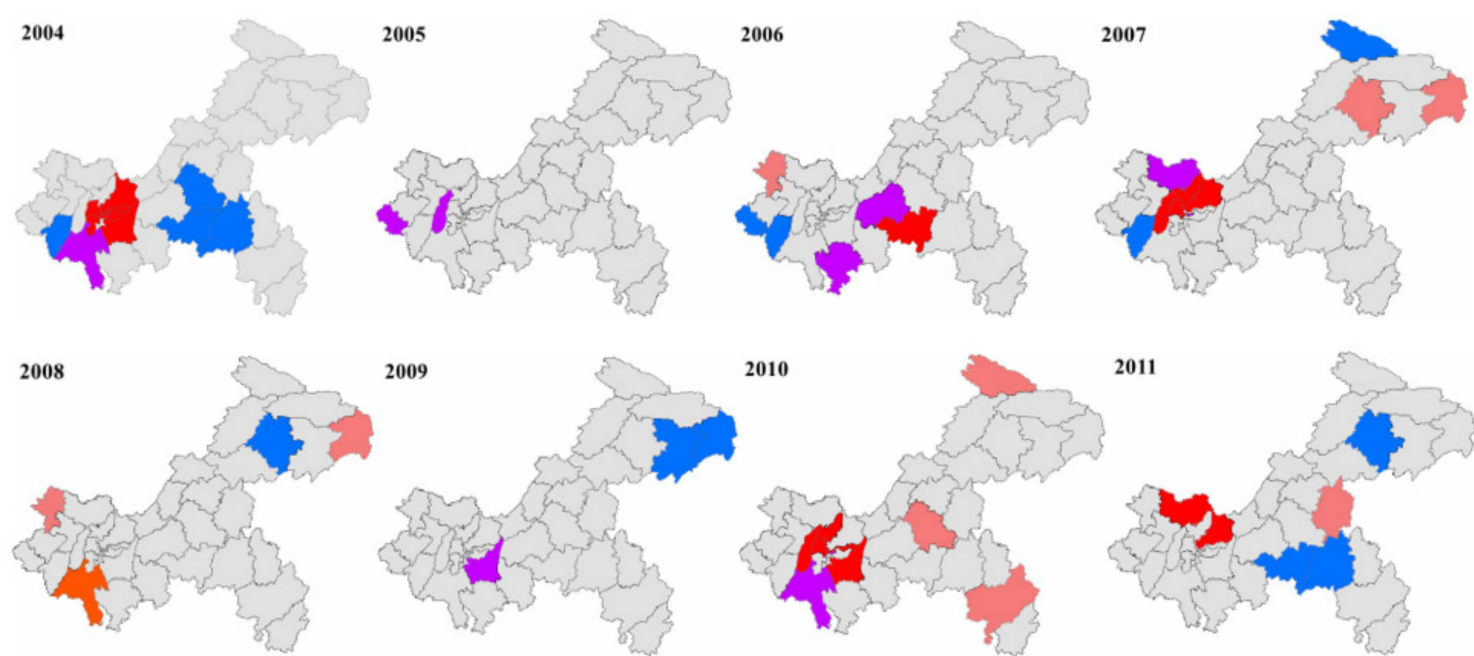

2010
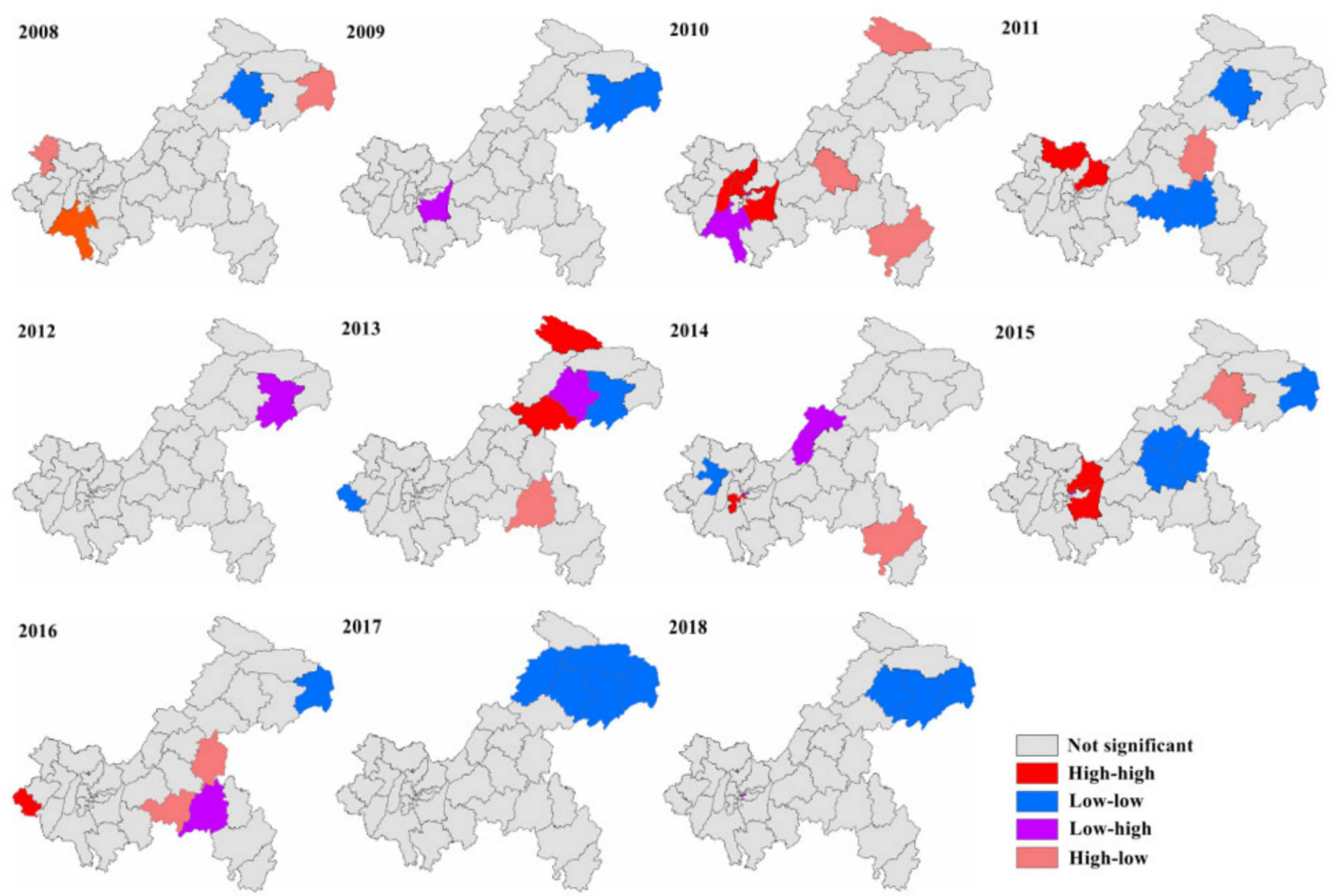

Figure 4. Yearly local spatial autocorrelation of mumps in Chongqing from 2004 to 2018. 
Table 2. Yearly spatial clusters of mumps cases in Chongqing from 2004 to 2018.

\begin{tabular}{|c|c|c|c|c|c|c|c|c|}
\hline Year & Cluster Type & $\begin{array}{c}\text { Counties } \\
\text { (n) }\end{array}$ & $\begin{array}{c}\text { Radius } \\
\text { (km) }\end{array}$ & $\begin{array}{l}\text { Observed } \\
\text { Cases }\end{array}$ & $\begin{array}{l}\text { Expected } \\
\text { Cases }\end{array}$ & $L L R$ & $R R$ & $p$-Value \\
\hline 2004 & Most likely & 8 & 31.61 & 5076 & 1894.39 & 2381.57 & 3.90 & $<0.001$ \\
\hline 2005 & Most likely & 4 & 47.62 & 2609 & 1295.83 & 600.37 & 2.31 & $<0.001$ \\
\hline 2006 & Most likely & 2 & 48.38 & 1083 & 327.65 & 587.66 & 3.77 & $<0.001$ \\
\hline \multirow{2}{*}{2007} & Most likely & 3 & 29.78 & 1152 & 367.10 & 604.56 & 3.79 & $<0.001$ \\
\hline & Secondary & 1 & 0 & 350 & 140.23 & 115.04 & 2.61 & $<0.001$ \\
\hline \multirow{2}{*}{2008} & Most likely & 1 & 0 & 1158 & 370.77 & 567.79 & 3.43 & $<0.001$ \\
\hline & Secondary & 1 & 0 & 702 & 262.61 & 261.85 & 2.81 & $<0.001$ \\
\hline \multirow{2}{*}{2009} & Most likely & 1 & 0 & 1760 & 688.26 & 622.52 & 2.77 & $<0.001$ \\
\hline & Secondary & 3 & 47.23 & 2306 & 1176.00 & 471.10 & 2.14 & $<0.001$ \\
\hline 2010 & Most likely & 8 & 48.38 & 4338 & 2561.94 & 647.21 & 1.99 & $<0.001$ \\
\hline 2011 & Most likely & 6 & 61.20 & 5575 & 3130.64 & 1001.61 & 2.16 & $<0.001$ \\
\hline \multirow{2}{*}{2012} & Most likely & 1 & 0 & 1111 & 229.92 & 899.31 & 5.18 & $<0.001$ \\
\hline & Secondary & 2 & 43.74 & 1123 & 457.40 & 360.55 & 2.59 & $<0.001$ \\
\hline 2013 & Most likely & 5 & 92.87 & 4216 & 2055.66 & 1092.64 & 2.54 & $<0.001$ \\
\hline \multirow{2}{*}{2014} & Most likely & 4 & 62.99 & 2147 & 1321.45 & 264.41 & 1.83 & $<0.001$ \\
\hline & Secondary & 5 & 24.54 & 1833 & 1121.74 & 223.30 & 1.80 & $<0.001$ \\
\hline 2015 & Most likely & 6 & 41.12 & 4513 & 1878.25 & 1739.22 & 3.36 & $<0.001$ \\
\hline \multirow{2}{*}{2016} & Most likely & 1 & 0 & 658 & 184.63 & 378.95 & 3.82 & $<0.001$ \\
\hline & Secondary & 1 & 0 & 362 & 83.80 & 256.92 & 4.49 & $<0.001$ \\
\hline \multirow{2}{*}{2017} & Most likely & 6 & 41.12 & 2599 & 1612.95 & 323.31 & 1.86 & $<0.001$ \\
\hline & Secondary & 2 & 45.44 & 1402 & 746.98 & 254.58 & 2.04 & $<0.001$ \\
\hline \multirow{2}{*}{2018} & Most likely & 1 & 0 & 629 & 261.38 & 195.58 & 2.55 & $<0.001$ \\
\hline & Secondary & 4 & 31.61 & 1466 & 904.21 & 175.21 & 1.80 & $<0.001$ \\
\hline
\end{tabular}

Abbreviations: $R R$-relative risk; $L L R$ - log likelihood ratio.

\subsection{Temporal and Space-Time Cluster Analysis}

The results of the purely temporal scan analysis showed that the time aggregation frame was from March 2009 to July 2013 ( $L L R=6936.16, p<0.001$ ). Spatiotemporal scan analysis detected four high-incidence clusters of mumps, including 18 counties in Chongqing, from 2004 to 2018. The most likely cluster, covering six counties, was mainly found in the west-central part of Chongqing from April 2011 to July $2011(L L R=3650.61, p<0.001)$. The secondary cluster $(n=5)$, second secondary cluster $(n=5)$, and third secondary cluster $(n=2)$ were located in the western, northeastern, and southwestern regions of Chongqing, respectively. The durations of all spatiotemporal clusters were recorded between April 2009 and July 2012 and were included in the temporal cluster detected by the purely temporal scan. The results of the spatiotemporal scan are detailed in Table 3 and mapped in Figure 6. 

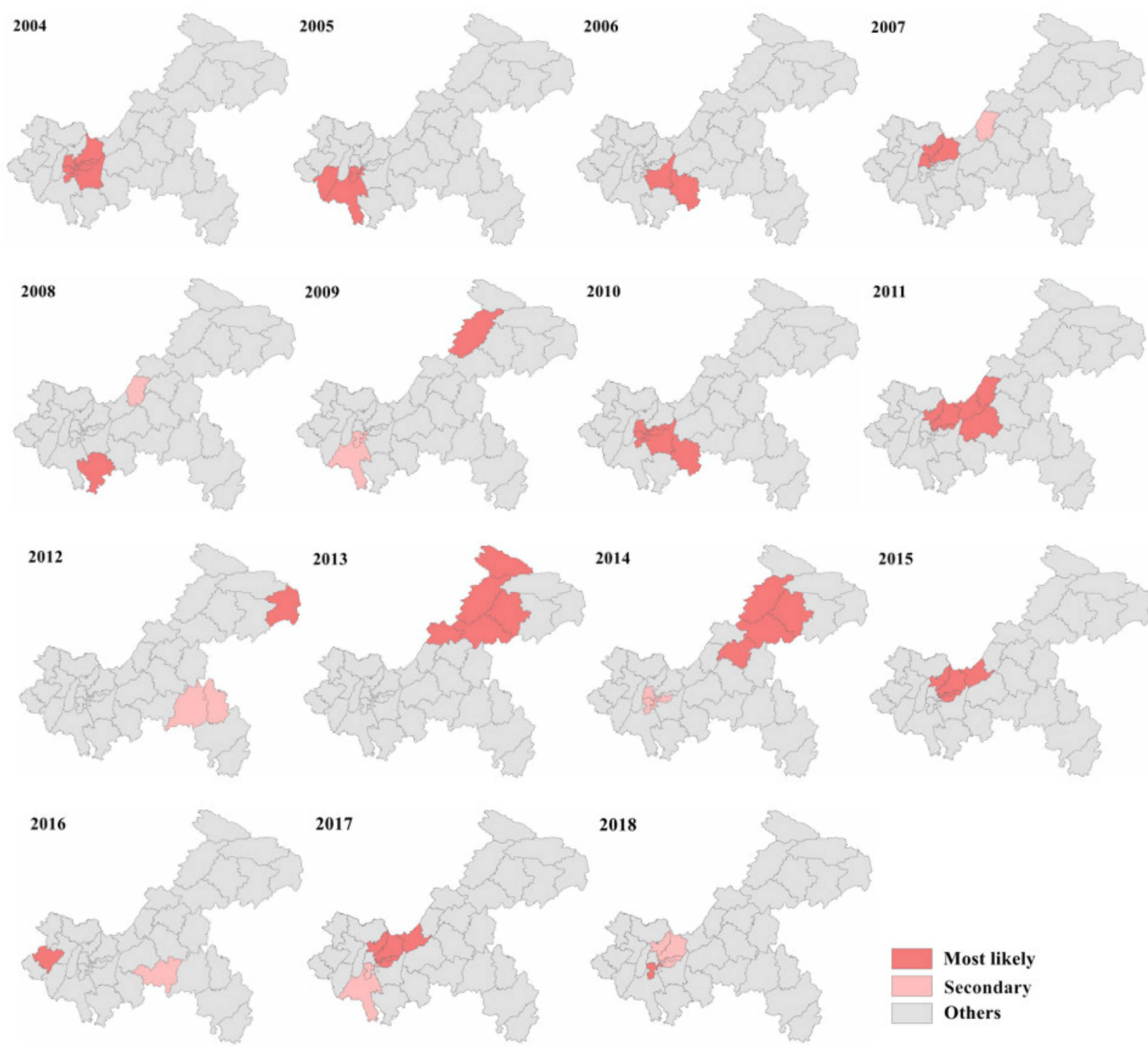

Figure 5. Yearly spatial clusters of mumps in Chongqing from 2004 to 2018.

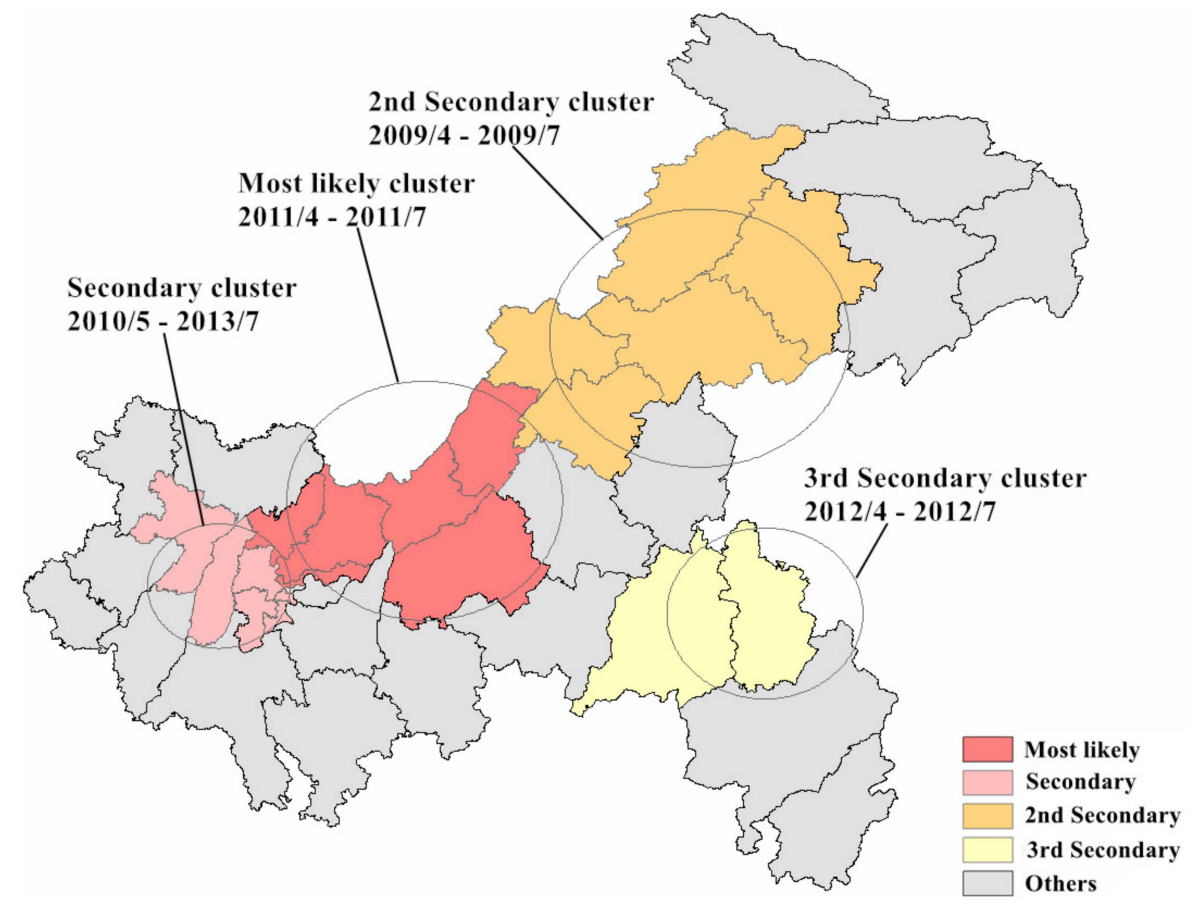

Figure 6. Spatiotemporal clusters of mumps in Chongqing from 2004 to 2018. 
Table 3. Spatiotemporal clusters of mumps cases in Chongqing from 2004 to 2018.

\begin{tabular}{ccccccccc}
\hline Cluster Type & Time Frame & $\begin{array}{c}\text { Counties } \\
(\mathbf{n})\end{array}$ & $\begin{array}{c}\text { Radius } \\
\mathbf{( k m )}\end{array}$ & $\begin{array}{c}\text { Observed } \\
\text { Cases }\end{array}$ & $\begin{array}{c}\text { Expected } \\
\text { Cases }\end{array}$ & LLR & RR & $\boldsymbol{p}$-Value \\
\hline Most likely & $\begin{array}{c}\text { April-July } \\
2011\end{array}$ & 6 & 61.20 & 3819 & 644.86 & 3650.61 & 6.04 & $<0.001$ \\
Secondary & $\begin{array}{c}\text { May 2010 to } \\
\text { July 2013 } \\
\text { April-July } \\
2009\end{array}$ & 5 & 31.83 & 9866 & 4148.18 & 2936.65 & 2.47 & $<0.001$ \\
Second Secondary & 5 & 66.04 & 3249 & 689.46 & 2497.72 & 4.79 & $<0.001$ \\
Third Secondary & $\begin{array}{c}\text { April-July } \\
2012\end{array}$ & 2 & 43.74 & 821 & 121.36 & 871.45 & 6.79 & $<0.001$ \\
\hline
\end{tabular}

\section{Discussion}

In this study, we described the epidemiology of mumps in Chongqing in terms of trends and the distribution of high-risk times and groups, and from a geographical point of view, we detected spatial, temporal, and spatiotemporal clusters. During the 15-year study period, the incidence of mumps fluctuated and presented a decreasing trend in general. Although the mumps vaccine was incorporated into the national immunization expansion plan in 2008 , the number of mumps cases was not rapidly and considerably brought under control. Several years passed before it showed a downward trend, which was the same as the incidence in the whole country and some other provinces $[25,33,34]$. This may be related to the accumulation of susceptible children who missed opportunities for vaccination for some reason, the age limit of the vaccinated population, and the periodicity of mumps [35-37]. The downward trend of mumps in the last few years indicated that the preventive and control measures were effective. Previous epidemiological studies of mumps in other regions $[24,38,39]$ have shown that the incidence among males is significantly higher than that among females, and the same was true of our findings, which may be due to differential behavioral patterns $[40,41]$. Males are relatively more active and less hygienic, which increases their exposure to the mumps virus. According to the one-dose MMR vaccination policy in 2008 for children aged 18-24 months, it was estimated that all children under the age of 5 after 2013 would be vaccinated free of charge. Therefore, in 2013-2018, the number of cases in children aged 0-4 years tended to be stable.

Children aged 5-9 years as the high-incidence population had a fluctuating incidence, which might be attributed to the congestion and high density of the school environments in which they live and the weakening of vaccine efficacy over time [36]. Indeed, the prevalence rates of three economically developed municipalities, namely, Beijing, Shanghai, and Tianjin, which introduced the two doses of the routine immunization program, were significantly lower than those of other provinces [33]. The epidemic situation of mumps in this study had a bimodal seasonal distribution, which was roughly consistent with the results of previous studies [24-26]. In China, both of these peaks occurred in the student's school term time, which was linked to the phenomenon that students were the main occupation of mumps patients. Hence, schools and kindergartens should strengthen health management for students and kindergarten children, strictly check their vaccination certificates at admission, and promote health knowledge education.

Studies have confirmed that potential climate factors such as temperature, humidity, and sunshine are significantly correlated with the incidence of mumps in other parts of China [39,42-44]. Chongqing, situated in the Chinese southeastern inland, has a different geographical location and climate, so the impact of climate on the disease may be different. Nevertheless, no such study has been carried out in Chongqing, and thus climate can be considered in the future to better predict the prevalence of mumps. Combining the incidence map with the results of global and local spatial autocorrelation analyses showed that the geographical distribution of mumps in Chongqing had spatial heterogeneity, but it was not as significant as that in previous studies [24-26]. Little deviation was noted between the locations of high-incidence areas detected by the spatial scan, space-time scan, and LISA map, but these locations were basically consistent. Given that the locations of high-risk clusters changed 
almost every year, it is necessary to carry out real-time space monitoring. There still existed some high-incidence regions of mumps, mainly in the midwestern, western, northeastern, and southwestern parts of Chongqing, particularly in the nine main urban districts and the counties close to the main urban zone. The temporal cluster determined by the purely temporal scan statistics was consistent with the observed high-prevalence years. In relatively developed urban regions, the higher incidence may be explained by the large population density, large population turnover, and diagnostic level. Some northeastern and southwestern counties, such as Chengkou, Pengshui, and Shizhu, located in mountainous areas with low socioeconomic status and insufficient health care services, also experienced high prevalence in certain years, which may have been caused by the untimely and low coverage of mumps vaccination $[45,46]$. The actual influencing factors of prevalence in high-incidence counties should be further studied in the future. In addition to the deficiencies of the current immunization policy itself, the two-dose routine immunization program has not been implemented, so the immunization level of the population is at a relatively low level of protection. In the results of the present study, the absence of a global spatial correlation did not mean that significant local clusters were nonexistent, and local autocorrelation analysis can reveal potentially masked local autocorrelation regions [47]. The LISA cluster map has the advantage of intuitively displaying truly local clustering regions. The principles and analytical variables of scan statistics and spatial autocorrelation methods to study the distribution of diseases from the perspective of GIS are different, so some dissimilarities also existed in the high-risk areas detected by each of them. In future studies, we can also consider combining the two methods to better and more completely grasp the geographical features of diseases.

Our findings may help public health agencies develop and improve effective prevention and control strategies and may provide evidence and clues for further research on the related risk factors for mumps. However, this study still has several limitations. First, the data quality of reported mumps cases was related to the monitoring sensitivity and management capacity of each regional system. This surveillance system is a passive information collecting system, which might lead to the underestimation of mumps cases, especially mild cases. Second, some meteorological and socioeconomic factors that may be associated with mumps epidemics were not included in this study for analysis, and so the cause of mumps could not be well explained.

\section{Conclusions}

The incidence of mumps in Chongqing was found to decline and reached a low level in 2018 after several fluctuations, with obvious seasonal variations. Children aged 5-9 years, males, and students were more susceptible to mumps virus. Although this study identified the spatial heterogeneity of mumps and the locations of high-risk areas, the high-incidence clusters varied year by year. Therefore, strengthening real-time spatial early monitoring and warning is required to better control and prevent mumps for targeting local endemic regions, especially at peak periods. Health-related policies should be formulated to take measures to implement intensive and compulsory vaccination, incorporate a second dose of mumps vaccine into routine vaccination procedures for higher and longer-lasting immunity among the young population, and allocate health resources more appropriately.

Author Contributions: Conceptualization, M.Y. and H.X.; Methodology, H.Z. (Hua Zhu), L.H. and D.J.; Software, H.Z. (Hua Zhu); Validation, R.O., D.J. and H.X.; Formal analysis, H.X.; Investigation, H.Z. (Han Zhao) and D.J.; Resources, H.Z. (Han Zhao); Data curation, L.H.; Writing—original draft preparation, H.Z. (Hua Zhu); Writing-review and editing, H.Z. (Hua Zhu), H.Z. (Han Zhao), M.S., R.O. and M.Y.; Visualization, H.X. and L.H.; Supervision, M.Y. and R.O.; Project administration, M.Y.

Funding: This research received no external funding.

Acknowledgments: The authors express their thanks to the Chongqing Municipal Center for Disease Control and Prevention for the disease data as well as the help from teachers at the Chongqing Medical University.

Conflicts of Interest: The authors declare no conflict of interest. 


\section{References}

1. Foy, H.; Cooney, M.; Hall, C.; Bor, E.; Maletzky, A. Isolation of mumps virus from children with acute lower respiratory tract disease. Am. J. Epidemiol. 1971, 94, 467-472. [CrossRef] [PubMed]

2. Philip, R.; Reinhard, K.; Lackman, D. Observations on a mumps epidemic in a virgin population. Am. J. Hyg. 1959, 69, 91-111. [PubMed]

3. Hviid, A.; Rubin, S.; Mühlemann, K. Mumps. Lancet 2008, 371, 932-944. [CrossRef]

4. Galazka, A.M.; Robertson, S.E.; Kraigher, A. Mumps and mumps vaccine: A global review. Bull. World Health Organ. 1999, 77, 3-14. [PubMed]

5. Marshall, H.S.; Plotkin, S. The changing epidemiology of mumps in a high vaccination era. Lancet Infect. Dis. 2019, 19, 118-119. [CrossRef]

6. Immunization Coverage. Available online: https://www.who.int/news-room/fact-sheets/detail/ immunization-coverage (accessed on 16 July 2018).

7. Fields, V.S.; Safi, H.; Waters, C.; Dillaha, J.; Capelle, L.; Riklon, S.; Wheeler, J.G.; Haselow, D.T. Mumps in a highly vaccinated Marshallese community in Arkansas, USA: An outbreak report. Lancet Infect. Dis. 2019, 19, 185-192. [CrossRef]

8. Vygen, S.; Fischer, A.; Meurice, L.; Mounchetrou Njoya, I.; Gregoris, M.; Ndiaye, B.; Ghenassia, A.; Poujol, I.; Stahl, J.P.; Antona, D.; et al. Waning immunity against mumps in vaccinated young adults, France 2013. Eurosurveillance 2016, 21, 30156. [CrossRef]

9. Aasheim, E.T.; Inns, T.; Trindall, A.; Emmett, L.; Brown, K.E.; Williams, C.J.; Reacher, M. Outbreak of mumps in a school setting, United Kingdom, 2013. Hum. Vaccines Immunother. 2014, 10, 2446-2449. [CrossRef]

10. Westphal, D.W.; Eastwood, A.; Levy, A.; Davies, J.; Huppatz, C.; Gilles, M.; Lyttle, H.; Williams, S.A.; Dowse, G.K. A protracted mumps outbreak in Western Australia despite high vaccine coverage: A population-based surveillance study. Lancet Infect. Dis. 2019, 19, 177-184. [CrossRef]

11. Cardemil, C.V.; Dahl, R.M.; James, L.; Wannemuehler, K.; Gary, H.E.; Shah, M.; Marin, M.; Riley, J.; Feikin, D.R.; Patel, M.; et al. Effectiveness of a Third Dose of MMR Vaccine for Mumps Outbreak Control. N. Engl. J. Med. 2017, 377, 947-956. [CrossRef]

12. Albertson, J.P.; Clegg, W.J.; Reid, H.D.; Arbise, B.S.; Pryde, J.; Vaid, A.; Thompson-Brown, R.; Echols, F. Mumps Outbreak at a University and Recommendation for a Third Dose of Measles-Mumps-Rubella Vaccine-Illinois, 2015-2016. Morb. Mortal. Wkly. Rep. 2016, 65, 731-734. [CrossRef] [PubMed]

13. Lewnard, J.A.; Grad, Y.H. Vaccine waning and mumps re-emergence in the United States. Sci. Transl. Med. 2018, 10. [CrossRef] [PubMed]

14. Marin, M.; Marlow, M.; Moore, K.L.; Patel, M. Recommendation of the Advisory Committee on Immunization Practices for Use of a Third Dose of Mumps Virus-Containing Vaccine in Persons at Increased Risk for Mumps During an Outbreak. Morb. Mortal. Wkly. Rep. 2018, 67, 33-38. [CrossRef] [PubMed]

15. Mumps Reported Cases by Country. Available online: http://apps.who.int/gho/data/view.main.1540_53? lang=en (accessed on 19 July 2018).

16. Shaw, N.; McGuire, S. Understanding the use of geographical information systems (GIS) in health informatics research: A review. J. Innov. Health Inform. 2017, 24, 940. [CrossRef] [PubMed]

17. O'Dwyer, L.A.; Burton, D.L. Potential meets reality: GIS and public health research in Australia. Aust. N. Z. J. Public Health 1998, 22, 819-823. [CrossRef]

18. Carroll, L.N.; Au, A.P.; Detwiler, L.T.; Fu, T.C.; Painter, I.S.; Abernethy, N.F. Visualization and analytics tools for infectious disease epidemiology: A systematic review. J. Biomed. Inform. 2014, 51, 287-298. [CrossRef] [PubMed]

19. Zhu, B.; Liu, J.; Fu, Y.; Zhang, B.; Mao, Y. Spatio-Temporal Epidemiology of Viral Hepatitis in China (2003-2015): Implications for Prevention and Control Policies. Int. J. Environ. Res. Public Health 2018, $15,661$. [CrossRef]

20. Dangisso, M.H.; Datiko, D.G.; Lindtjorn, B. Spatio-temporal analysis of smear-positive tuberculosis in the Sidama Zone, southern Ethiopia. PLoS ONE 2015, 10, e0126369. [CrossRef]

21. Soto-Calle, V.; Rosas-Aguirre, A.; Llanos-Cuentas, A.; Abatih, E.; DeDeken, R.; Rodriguez, H.; Rosanas-Urgell, A.; Gamboa, D.; Umberto, D.; Erhart, A.; et al. Spatio-temporal analysis of malaria incidence in the Peruvian Amazon Region between 2002 and 2013. Sci. Rep. 2017, 7, 40350. [CrossRef] 
22. Zhang, Q.; Liu, W.; Ma, W.; Shi, Y.; Wu, Y.; Li, Y.; Liang, S.; Zhu, Y.; Zhou, M. Spatiotemporal epidemiology of scarlet fever in Jiangsu Province, China, 2005-2015. BMC Infect. Dis. 2017, 17, 596. [CrossRef]

23. Gui, J.; Liu, Z.; Zhang, T.; Hua, Q.; Jiang, Z.; Chen, B.; Gu, H.; Lv, H.; Dong, C. Epidemiological Characteristics and Spatial-Temporal Clusters of Hand, Foot, and Mouth Disease in Zhejiang Province, China, 2008-2012. PLoS ONE 2015, 10, e0139109. [CrossRef] [PubMed]

24. Li, R.; Cheng, S.; Luo, C.; Rutherford, S.; Cao, J.; Xu, Q.; Liu, X.; Liu, Y.; Xue, F.; Xu, Q.; et al. Epidemiological Characteristics and Spatial-Temporal Clusters of Mumps in Shandong Province, China, 2005-2014. Sci. Rep. 2017, 7, 46328. [CrossRef] [PubMed]

25. Yu, G.; Yang, R.; Wei, Y.; Yu, D.; Zhai, W.; Cai, J.; Long, B.; Chen, S.; Tang, J.; Zhong, G.; et al. Spatial, temporal, and spatiotemporal analysis of mumps in Guangxi Province, China, 2005-2016. BMC Infect. Dis. 2018, 18, 360. [CrossRef] [PubMed]

26. Liu, D.; Meng, L.; Gou, F.; Wei, K.; Yang, X.; Liu, X. Spatial temporal distribution of mumps in Gansu, 2009-2013. Zhonghua Liu Xing Bing Xue Za Zhi 2015, 36, 1258-1262. [PubMed]

27. Wang, L.; Wang, Y.; Jin, S.; Wu, Z.; Chin, D.P.; Koplan, J.P.; Wilson, M.E. Emergence and control of infectious diseases in China. Lancet 2008, 372, 1598-1605. [CrossRef]

28. Bureau of Disease Control and Prevention. Available online: http://www.nhc.gov.cn/jkj/s3577/201511/ f5d2ab9a5e104481939981c92cb18a54.shtml (accessed on 29 October 2015).

29. Luc, A. Local Indicators of Spatial Association-LISA. Geogr. Anal. 2010, 27, 93-115.

30. Ord, J.K.; Getis, A. Local Spatial Autocorrelation Statistics: Distributional Issues and an Application. Geogr. Anal. 2010, 27, 286-306. [CrossRef]

31. Tango, T.; Takahashi, K. A flexibly shaped spatial scan statistic for detecting clusters. Int. J. Health Geogr. 2005, 4, 1-15. [CrossRef]

32. Anselin, L.; Mccann, M. OpenGeoDa, open source software for the exploration and visualization of geospatial data. Proceedings of Acm Sigspatial International Symposium on Advances in Geographic Information Systems, Seattle, WA, USA, 4-6 November 2009; pp. 550-551.

33. Jiang, R.J.; Yin, Q.Z.; Xu, M.J.; Zhao, Z.M.; Deng, Y.; Che, Y.C. Epidemiological characteristics of mumps in mainland China from 2004 to 2018 and key population for prevention and control. Zhongguo Dang Dai Er Ke Za Zhi 2019, 21, 441-444.

34. Li, D.; Chen, Z.F.; Yang, X.H.; Pan, W.Y.; Wang, Q.; Zhang, S.H.; Zheng, N.X.; Huang, L.F.; Zhou, Y. Epidemiological and pathogenic characteristics of mumps in Fujian province, 2005-2017. Zhonghua Liu Xing Bing Xue Za Zhi 2018, 39, 1356-1361. [CrossRef]

35. Mokdad, A.H.; Gagnier, M.C.; Colson, K.E.; Dansereau, E.; Zúñiga-Brenes, P.; Ríos-Zertuche, D.; Haakenstad, A.; Johanns, C.K.; Palmisano, E.B.; Hernandez, B.; et al. Missed Opportunities for Measles, Mumps, and Rubella (MMR) Immunization in Mesoamerica: Potential Impact on Coverage and Days at Risk. PLoS ONE 2015, 10, e0139680. [CrossRef] [PubMed]

36. Wang, H.; Hu, Y.; Zhang, G.; Zheng, J.; Li, L.; An, Z. Meta-analysis of vaccine effectiveness of mumps-containing vaccine under different immunization srategies in China. Vaccine 2014, 32, 4806-4812. [CrossRef] [PubMed]

37. Barskey, A.E.; Glasser, J.W.; LeBaron, C.W. Mumps resurgences in the United States: A historical perspective on unexpected elements. Vaccine 2009, 27, 6186-6195. [CrossRef] [PubMed]

38. Sane, J.; Gouma, S.; Koopmans, M.; De Melker, H.; Swaan, C.; Van Binnendijk, R.; Hahne, S. Epidemic of mumps among vaccinated persons, The Netherlands, 2009-2012. Emerg. Infect. Dis. 2014, 20, 643-648. [CrossRef] [PubMed]

39. Yang, Q.; Yang, Z.; Ding, H.; Zhang, X.; Dong, Z.; Hu, W.; Liu, X.; Wang, M.; Hu, G.; Fu, C. The relationship between meteorological factors and mumps incidence in Guangzhou, China, 2005-2012. Hum. Vaccines Immunother. 2014, 10, 2421-2432. [CrossRef] [PubMed]

40. Muenchhoff, M.; Goulder, P.J. Sex differences in pediatric infectious diseases. J. Infect. Dis. 2014, 209 (Suppl. 3), S120-S126. [CrossRef]

41. Van Lunzen, J.; Altfeld, M. Sex differences in infectious diseases-common but neglected. J. Infect. Dis. 2014, 209 (Suppl. 3), S79-S80. [CrossRef]

42. Hu, W.; Li, Y.; Han, W.; Xue, L.; Zhang, W.; Ma, W.; Bi, P. Meteorological factors and the incidence of mumps in Fujian Province, China, 2005-2013: Non-linear effects. Sci. Total Environ. 2018, 619-620, 1286-1298. [CrossRef] 
43. Ho, Y.C.; Su, B.H.; Su, H.J.; Chang, H.L.; Lin, C.Y.; Chen, H.; Chen, K.T. The association between the incidence of mumps and meteorological parameters in Taiwan. Hum. Vaccines Immunother. 2015, 11, 1406-1412. [CrossRef]

44. Li, R.; Lin, H.; Liang, Y.; Zhang, T.; Luo, C.; Jiang, Z.; Xu, Q.; Xue, F.; Liu, Y.; Li, X. The short-term association between meteorological factors and mumps in Jining, China. Sci. Total Environ. 2016, 568, 1069-1075. [CrossRef]

45. Gram, L.; Soremekun, S.; Ten Asbroek, A.; Manu, A.; O’Leary, M.; Hill, Z.; Danso, S.; Amenga-Etego, S.; Owusu-Agyei, S.; Kirkwood, B.R. Socio-economic determinants and inequities in coverage and timeliness of early childhood immunisation in rural Ghana. Trop. Med. Int. Health 2014, 19, 802-811. [CrossRef] [PubMed]

46. Hu, Y.; Wang, Y.; Chen, Y.; Li, Q. Determinants of inequality in the up-to-date fully immunization coverage among children aged 24-35 months: Evidence from Zhejiang province, East China. Hum. Vaccines Immunother. 2017, 13, 1902-1907. [CrossRef] [PubMed]

47. Huang, L.; Pickle, L.W.; Das, B. Evaluating spatial methods for investigating global clustering and cluster detection of cancer cases. Stat. Med. 2008, 27, 5111-5142. [CrossRef] [PubMed]

(C) 2019 by the authors. Licensee MDPI, Basel, Switzerland. This article is an open access article distributed under the terms and conditions of the Creative Commons Attribution (CC BY) license (http://creativecommons.org/licenses/by/4.0/). 